\section{Summary points}

Removing user fees for primary care is important in offering financial protection to poor African households

Fee removal must be accompanied by increased national budgets for health care to protect the quality of health care in the face of increased utilisation

Careful and deliberate implementation strategies are needed to ensure that fee removal achieves its objectives

National action must be supported by international action that is sensitive to national circumstances and underpins the sustained mobilisation of resources

Health in Southern Africa, EQUINET, and HEPNet, the Health Economics and Policy Network in Africa). It responds to current calls, such as those of the Africa Commission, for the removal of primary care user fees in Africa. An earlier, substantively different, version of this piece was prepared by the authors as an editorial for the electronic newsletter of EQUINET.

Competing interests: None declared.

Gilson L. The lessons of user fee experience in Africa. Health Policy Pla 1997; 12:273-85.

2 Commission for Africa. Our common interest: report of the Commission for Africa. London: Commission for Africa, 2005. www. commissionforafrica.org/english/report/thereport/english/11-03-05 cr report.pdf (accessed 19 May 2005).

Van Doorslaer $\mathrm{E}$, Wagstaff A. Equity in the finance of health care: meth ods and findings. In: Van Doorslaer E, Wagstaff A, Rutten F, eds. Equity in the finance and delivery of health care: An international perspective. New York: Oxford University Press, 1993.

4 Russell S. The economic burden of illness for households in developing countries: a review of studies focusing on malaria, tuberculosis and human immunodeficiency virus/acquired immunodeficiency syndrome. Am J Trop Med Hyg 2004;7(suppl 2):147-55.

5 James C, Morris SS, Keith R, Taylor A. Impact on child mortality of removing user fees: simulation model. BMJ 2005;331:747-9.

6 McIntyre D, Thiede M, Dahlgren G, Whitehead M. What are the economic consequences for households of illness and of paying for health care in low- and middle-income country contexts? Soc Sci Med (in press).

7 Tibandebage P, Mackintosh M. The market shaping of charges, trust and Thuse:

Deininger K, Mpuga P. Economic and welfare effects of the abolition of health user fees: evidence from Uganda. Washington, DC: World Bank, 2004. (World Bank policy research working paper 3276.)

McCoy D. Free health care for pregnant women and children under six in South Africa: an impact assessment. Durban: Health Systems Trust, 1996.

10 World Health Organization. World health report-NHA annexes. www. who.int/nha/country/whrannex/en (accessed 14 Sep 2005).

11 EQUINET Steering Committee (Regional Network for Equinet in Health in Southern Africa). Reclaiming the state: achieving people's health, challenging injustice. Harare: EQUINET, 2004. (EQUINET policy series No 15.)

12 McIntyre D, Muirhead D, Gilson L. Geographic patterns of deprivation and health inequities in South Africa: informing health equity analyses and health inequities in South Africa: informing health equity analyses
and public resource allocation strategies. Health Policy Plan 2002;17(suppl and public resource allocation strategies. Health Policy Plan 2002;17 (supp 1):30-9.

13 Gilson L, Mills A. Health sector reform in sub-Saharan Africa: lessons of the last ten years. Health Policy 1995;32:215-43.

14 Gilson L, Doherty J, Lake S, McIntyre D, Mwikisa C, Thomas S. The SAZA study: implementing financing reform in South Africa and Zambia. Health Policy Plan 2003;18:31-46.

15 Osborne SP, Brown K. Managing change and innovation in public service organizations. London: Routledge, 2005.

16 Gilson L, Travis P. Health system decentralization in Africa: an overview of experiences in eight countries. Geneva: World Health Organization, 1997. (Background document prepared for the regional meeting on decentralization in the context of health sector reform in Africa.)

17 McIntyre D, Klugman B. The human face of decentralisation and integraMcIntyre D, Klugman B. The human face of decentralisation and integra-
tion of health services: experience from South Africa. Reprod Health Mat tion of health services: expe
ters 2003;11(21):108-19.

18 Walker L, Gilson L. We are bitter but we are satisfied: nurses as street level bureaucrats in South Africa. Soc Sci Med 2004;59:1251-61.

19 Gilson L, Palmer N, Schneider H. Trust and health worker performance: exploring a conceptual framework using South African evidence. Soc Sci Med 2005;61:1418-29.

20 Burnham G, Pariyo G, Galiwango E, Wabwire-Mangen F. Discontinuation of cost sharing in Uganda. Bull World Health Org 2004;82:187-95.

21 Joint Learning Initiative. Human resource for health: overcoming the crisis. Boston: Global Health Equity Initiative, 2004.

\title{
System and market failures: the unavailability of magnesium sulphate for the treatment of eclampsia and pre-eclampsia in Mozambique and Zimbabwe
}

\author{
E Sevene, S Lewin, A Mariano, G Woelk, A D Oxman, S Matinhure, J Cliff, B Fernandes, K Daniels
}

Low cost and effective drugs, such as magnesium sulphate, need to be included in initiatives to improve access to essential medicines in Africa

Ensuring the availability of effective drugs for priority health problems remains a key public health issue in many African countries. ${ }^{1}$ Market deficiencies in ensuring drug development for "neglected" diseases affecting developing countries are well described, ${ }^{23 \mathrm{w} 1}$ and several global initiatives are attempting to tackle this. ${ }^{4}$ 2 $2 v e n$ when low cost, effective treatments exist, however, drug availability for many common health problems remains poor in many settings, limiting progress towards achieving the millennium development goals.

One such health problem is the management of pre-eclampsia and eclampsia, important causes of maternal and infant morbidity and mortality. Over
63000 women die annually after eclamptic convulsions, with $99 \%$ of these deaths occurring in low and middle income countries. ${ }^{67 \mathrm{w} 3}$

Evidence is strong for the effectiveness of magnesium sulphate in treating and preventing eclampsia. $^{8-10}$ w4 w5 Magnesium sulphate costs $\$ 0.35$ (£0.19; €0.29) per ampoule ( $40 \mathrm{ml}$ of $10 \%$ magnesium sulphate; Central Medical Stores, Mozambique, April 2005) and has appeared on the World Health Organization's essential medicines list since $1996 .{ }^{11}$ It is of great concern that this effective and low cost drug is

Details of drug regulation, web references w1-w9, and Table 2 are on bmj.com
Department of
Pharmacology, Faculty of Medicine, Eduardo Mondline, University, Mozambique E Sevene pharmacologist A Mariano pharmacologist $\mathrm{J}$ Cliff professor continued over 
Department of Community Medicine, University of Zimbabwe, Zimbabwe

G Woelk associate professor S Matinhure researcher

Norwegian Knowledge Centre for Health Services, Norway

A D Oxman

researcher

National Institute of Health, Ministry of Health,

Mozambique

B Fernandes health systems researcher

Health Systems Research Unit,

Medical Research Council of South Africa

K Daniels scientist

$\mathrm{S}$ Lewin lecturer

Correspondence to: Simon Lewin, Department of Public Health and Policy, London School of Hygiene and Tropical Medicine, London WC1E 7HT simonlewin@ lshtm.ac.uk

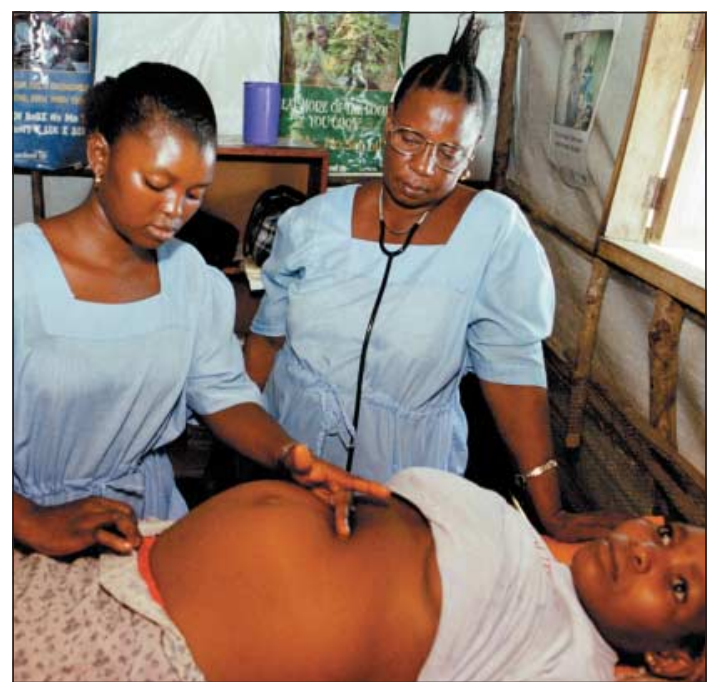

A pregnant woman has a check up at a clinic in a camp for internally displaced people

still unavailable in many countries. ${ }^{12}{ }^{13}$ w6 w7 We describe problems with the registration, approval, acquisition, and distribution of magnesium sulphate, and hence its availability to clinicians, in Mozambique and Zimbabwe, two countries with high maternal mortality ratios (table). ${ }^{14-16}$ We draw on a range of sources, including a bibliographical review of policies concerning magnesium sulphate over the past 25 years and qualitative data collected as part of a case study of policy making and procurement for magnesium sulphate in the two countries (box 1), ${ }^{17}$ to argue that drug availability has been affected by system and market failures.

Why is magnesium sulphate not widely available in Mozambique and Zimbabwe?

\section{Mozambique}

Magnesium sulphate has been used in Mozambique's Maputo Central Hospital since 1981, well before rigorous evidence of its effectiveness became available. An obstetric guideline published in 1985 described magnesium sulphate as the first line drug for treating eclampsia. Until recently, however, it was unavailable outside the hospital, and other drugs, including diazepam, continue to be used as first line treatment.

The key reasons for this lie in the complex mechanisms of approval, acquisition, and distribution of drugs in Mozambique (see bmj.com). The national formulary of medicines lists the essential drugs that can be acquired by, and distributed through, Mozambique's national health system. The 1980 edition did not include magnesium sulphate and this was not updated until 1999. In this period the Central Medical Stores compiled a list of purchases that included both the medicines listed in the formulary and other drugs that

Maternal mortality ratios in Mozambique and Zimbabwe

\begin{tabular}{lcc} 
Country & Maternal mortality ratio* & $\begin{array}{c}\text { Proportion of mortality } \\
\text { attributable to eclampsia } \\
\text { (\%) }\end{array}$ \\
\hline Mozambique & 1000 & 3.2 to $11.3^{15} \mathrm{w8} \dagger$ \\
\hline Zimbabwe & 1100 & $6.9^{16}$ \\
\hline
\end{tabular}

*Number of maternal deaths per 100000 live births. ${ }^{14}$

tRobust national estimates are not available. Range given is based on estimates provided in listed studies. clinicians regarded as necessary. Magnesium sulphate had not been requested by clinicians, however, and was therefore not included. This meant that it had to be ordered locally, but this was only done by the Maputo Central Hospital, and only when funds were available. During this period, economic constraints resulting from the war affected the availability of many drugs, particularly those not on the list of the Central Medical Stores. In addition, pharmaceutical companies were poorly represented in Mozambique at this time and participated only in international competitive tenders.

When the formulary was updated in 1999 it was decided that medicines for specialist and hospital use would be included in a special appendix to better control their use. Although magnesium sulphate was seen as important for the management of eclampsia, there was consensus that it should appear only in this list. For reasons that remain unclear, this appendix was not included in the Central Medical Store's list of purchases when the new formulary came into force. Medicines in this appendix could still be acquired, but required special import procedures, including a request by clinicians, review by the Therapeutic Commission, and authorisation from the Ministry of Health. This was a major barrier to procurement.

Box 1: Methods used for case study of policy making and procurement for magnesium sulphate in Mozambique and Zimbabwe

\section{Data collection approach}

- In-depth, semistructured qualitative interviews and informal discussions covering:

The structure and process of policy making for the management of eclampsia and pre-eclampsia

Factors affecting the implementation of policies on the issues of interest

Individual's knowledge of evidence related to the use of magnesium sulphate in the treatment of eclampsia and pre-eclampsia

Summary of methods used for case study of magnesium sulphate policy making and procurement in Mozambique and Zimbabwe

\begin{tabular}{lcc}
\multicolumn{3}{c}{ Characteristics of respondents } \\
\hline $\begin{array}{c}\text { No in } \\
\text { Mosition }\end{array}$ & $\begin{array}{c}\text { No in } \\
\text { Zimbabwe }\end{array}$ \\
\hline Clinicians or researchers & 4 & 7 \\
\hline Senior Ministry of Health officials & 2 & 2 \\
\hline Therapeutic Commission & 2 & 2 \\
\hline Medicine Control Authority & 1 & 2 \\
\hline $\begin{array}{l}\text { Pharmacist } \\
\begin{array}{l}\text { Pharmaceutical company } \\
\text { representatives }\end{array}\end{array}$ & - & 3 \\
\hline
\end{tabular}

Sampling

- Purposive and snowballing approach, based on respondents' involvement in policy making or procurement for magnesium sulphate

Data analysis

- All interviews audio recorded and transcribed

- Categories emerging from the data identified and a coding frame developed

- Coding frame applied to all transcripts

- Country level themes compared and similarities and differences identified 
Discussions in 2001 between clinicians, Ministry of Health departments, and the Therapeutic Commission culminated in authorisation for the central purchasing of magnesium sulphate. Since 2003 the drug has been distributed to peripheral units, but again only when requested by the local clinicians. Routine data show that these requests have been sporadic.

In discussing these ongoing problems with the approval, acquisition, and distribution of magnesium sulphate since the publication of the landmark collaborative eclampsia trial in 1995, obstetrician respondents claimed that although they had contributed to the development of guidelines for obstetric care, including the management of eclampsia, and had trained health professionals in using magnesium sulphate, they did not have the authority to ensure a countrywide implementation of the guidelines.

Respondents from Central Medical Stores, however, noted that these problems were the result of obstetricians not requesting the drug. Poor communication between the two groups seemed, then, to be an important obstacle to improving drug availability. Even after formal approval of the drug, difficulties with distribution and management gave the impression to clinicians that the drug was still unavailable. As a result, they continued to use alternative treatments and did not request magnesium sulphate from the Central Medical Stores or the pharmacy in their own health unit.

\section{Zimbabwe}

Magnesium sulphate has long been used for the treatment of eclampsia in Zimbabwe, including at Harare Central Hospital since at least 1984-5 (see table on bmj.com). It is still not registered for this use, however, and was listed in 2000 in the essential drugs list as a second line therapy for eclampsia. Respondents cited four key reasons for this. Firstly, the effects of insufficient capacity and resources within the Ministry of Health and Child Welfare: as foreign currency resources are limited, the ministry decided that local (that is, hospital based) arrangements should be made to acquire what they described as "orphan" drugsthose required mainly by hospital based specialists. Priority for central purchasing is given to first line drugs used at all levels of the health service. It was also suggested that the Ministry of Health and Child Welfare does not have sufficient qualified clinicians to monitor drug use or even to prescribe the drug in peripheral hospitals.

Secondly, the ministry and professional obstetric organisations failed to ensure the registration of magnesium sulphate with the Medicine Control Authority of Zimbabwe: the drug was not seen as a priority because it was perceived to be slow moving and because pharmacists at the Ministry of Health and Child Welfare thought that other drugs, such as diazepam, could be substituted.

Thirdly, pharmaceutical companies lacked financial incentives to push for registration and importation: several respondents noted that the low cost of magnesium sulphate, coupled with the low potential volume of use, resulted in low returns. It is unclear to what extent drug registration fees, currently $\mathrm{Z} \$ 5 \mathrm{~m}$ (£277; \$500; €409) for Zimbabwean applicants per drug or US $\$ 1000$ for foreign applicants per drug, are a barrier. Although relatively low by international stand- ards, ${ }^{18}$ these fees, together with the costs of preparing a submission and bureaucratic barriers, may dissuade commercial companies from applying for registration in this small market.

Finally, clinicians' perceptions of the dangers of magnesium sulphate may have contributed to the drug's non-use. Respondents acknowledged that the international trials in which Zimbabwe collaborated showed clearly that the drug saves lives. They also noted, however, that the belief of many Zimbabwean clinicians in the drug's effectiveness is tempered by their perceptions of its dangers to women. This was seen to contribute to its second line listing in the essential drugs list.

Respondents highlighted several other factors affecting the availability of magnesium sulphate. These included the lack of a clinical champion, poor communication between clinicians and pharmacy staff, the ambiguity of clinical guidelines from the Ministry of Health and Child Welfare on the use of magnesium sulphate, inadequate dissemination of guidelines, clinicians' long use of other drugs to manage eclampsia, and constraints on human resources. Consequently, diazepam continues to be used by many clinicians in Zimbabwe as first line therapy for the management of eclampsia.

Although magnesium sulphate remains unregistered, clinicians have since convinced the Medicine Control Authority of Zimbabwe, the Ministry of Health and Child Welfare, and the National Drug and Therapeutic Policy Advisory Committee of its usefulness. It can, therefore, be used without registration but still has to be requested by clinicians from their local pharmacy - a process that depends on the availability of local resources.

\section{System and market failures in ensuring the availability of magnesium sulphate}

The issues affecting the availability of magnesium sulphate can be divided broadly into the two categories of system and market failures. We identified several key system failures. Firstly, issues related to drug registration were important in both countries. In Zimbabwe,

Box 2: Criteria for and barriers to the operation of a free market for magnesium sulphate in Mozambique and Zimbabwe

Many independent producers and consumers

Only one major consumer of the drug-the central government purchaser-is responsible for national acquisition

Full information on both sides about prices and quality

Asymmetries in information exist as the central purchaser does not assess need for the drug among clinicians and is therefore unaware of demand.

The central purchaser also does not receive information from the producers on drug effectiveness

No external effects (that is, costs or benefits accruing to individuals or groups other than those undertaking the activity)

If a pharmaceutical company marketed a low cost generic dug such as magnesium sulphate, this could increase the market share of other companies producing the drug - that is, positive external effects. In contrast, branded products have higher profit margins as other companies are legally prevented from selling the same drug. Marketing thus increases the sales of the branded product only.

Incentives are few under a central tendering system for companies to market drugs to clinicians 


\section{Box 3: Recommendations to improve the availability of} magnesium sulphate

- Governments need to ensure that:

Bureaucratic processes do not obstruct the delivery of low cost, effective drugs

Mechanisms are put in place for improved communication between

clinicians and agencies responsible for drug procurement and supply at country level

- WHO, international professional organisations such as FIGO

(International Federation of Gynaecology and Obstetrics), and international donor agencies, should take a more active role in ensuring that all essential medicines are registered and available in developing countries

- Pharmaceutical companies need to be engaged in initiatives to ensure the supply of low cost, effective drugs for common conditions in Africa; financial and other incentives for marketing these drugs need to be considered by international agencies

- When the conditions for a functional market for pharmaceuticals are not met, governments must be prepared to intervene to support public health, and international organisations should support them in this long delays in registration were described. In Mozambique, the absence of a registration mechanism before 2001 resulted in the development of a complex drug procurement process, with many opportunities for failure. Secondly, long delays occurred in both countries in including magnesium sulphate in their national formularies. Because drug purchasing is based on these formularies, any failure to include effective drugs such as magnesium sulphate is critical. Thirdly, the numerous opportunities for communication failure within the bureaucratic processes of drug registration, inclusion in the formulary, acquisition, and distribution further contributed to the poor availability of magnesium sulphate. The earlier and current economic difficulties in Mozambique and Zimbabwe, respectively, also affected the procurement of drugs.

As magnesium sulphate is a cheap generic drug, its cost should not be a barrier to its availability in a free market. For a free market to operate, several criteria need to be fulfilled (box 2) ${ }^{19}$ It is not unusual for some or all of these criteria not to be met, but the more marked the departure from these criteria, the less likely that a market can function. Several of these criteria were not met for magnesium sulphate in Mozambique or Zimbabwe (box 3), suggesting that market failure contributed to the poor availability of the drug. Similar failures have been described for other pharmaceuticals elsewhere, ${ }^{20}$ w8 including for other cheap, effective drugs such as thiazides ${ }^{\mathrm{w} 9}$ and ibuprofen. ${ }^{20}$

The low cost of magnesium sulphate had several paradoxical effects. It was suggested that its price retarded its registration in Zimbabwe, as the potentially small profits provided little economic incentive for companies to incur registration costs. Respondents in Mozambique noted similarly that because the drug was cheap and the potential profits from it low, pharmaceutical companies did not actively market it or promote it to the central purchaser.

These problems seem to have been compounded by the lack of economies of scope for the drug. The market for magnesium sulphate is relatively small and the drug is not widely used for other conditions. Economies of scale are also unlikely, given that eclampsia is relatively uncommon and that the drug is already low cost. Economies of scope are important to both the health system and the manufacturer-they give additional incentives to the purchaser to consider the drug and they increase the size of the market (and hence opportunities for profit) for the manufacturer. Alternative drugs for the treatment of eclampsia, while substantially less effective, are also cheap and used widely for other conditions. They are therefore generally available at health unit level, and pharmaceutical companies do not incur costs in promoting them.

\section{Conclusions}

The complexity of drug approval, acquisition, and distribution mechanisms in Mozambique and Zimbabwe results in many opportunities for system failures. Cost is also an important factor in the availability of magnesium sulphate, but not because the drug is expensive. Rather, its low cost means that market forces cannot be relied on to ensure its availability in these settings. Box 3 outlines several recommendations to address these system and market failures.

As initiatives are developed to ensure wider access to expensive drugs critical to improving public health in Africa, low cost and effective drugs such as magnesium sulphate for treating eclampsia, should not be forgotten.

We thank the participants; John Lavis, Cecilia Stalsby-Lundberg, and Gill Walt for advice on the study design and analysis; Morten Aaserud, Iain Chalmers, Jo Chirenda, Lelia Duley, David Henry, Jane Ritchie, Luke Vale, and Gill Walt for comments on draft papers; Lelia Duley for background information on magnesium sulphate; Sylvia Louw and Aud Ingeborg Urdahl for administrative support; and the EU Practihc (pragmatic randomised trials in health care) project group. JC holds a joint appointment between the Department of Community Health, Eduardo Mondlane University, Mozambique, and Monash University, Melbourne, Australia.

Contributors and sources: This article arose from discussions within our research team while conducting a study of the use of research evidence in policy making in Mozambique, South Africa and Zimbabwe. GW, JC, and SL designed the study. SM, ES, and AM collected the data. ES, SM, AM, JC, and GW led the

\section{Summary points}

Evidence from randomised controlled trials shows that magnesium sulphate, a low cost drug, is effective for the treatment of eclampsia and pre-eclampsia

The drug, like many other effective treatments, is still not available widely in many low and middle income countries, but the reasons for this remain unclear

Failures in the registration, procurement, and distribution mechanisms for magnesium sulphate contribute to its poor availability in Mozambique and Zimbabwe

In addition, the low cost of magnesium sulphate means that market forces cannot be relied on to ensure its availability

Governments and international agencies must be prepared to intervene to ensure the availability of low cost, effective drugs in developing countries 
analysis, to which the other authors contributed. ES, SL, and $\mathrm{ADO}$ led the writing of the paper, to which the other authors contributed. ES and SL are guarantors.

Funding: Funding was provided by the Alliance for Health Policy and Systems Research (ID-3.115), German Technical Development (PN: 95.2068.5-001.00), and the European Commission funded Practihc (pragmatic randomised trials in health care) project (ICA4-CT-2001-10019). Additional funding for the study collaborators was provided by the Medical Research Council of South Africa. The study sponsors approved the study design but played no part in the collection, analysis, and interpretation of data; in the writing of the report; or in the decision to submit the paper for publication.

Competing interests: None declared.

Ethical approval: This study was approved by the Comite Nacional de Bioética para a Saúde in Mozambique, the Medical Research Council of Zimbabwe, and the ethics committees of the London School of Hygiene and Tropical Medicine and WHO. Written consent was obtained from all respondents following discussion of the study and provision of an information sheet.

1 World Health Organization. Commission on Macroeconomics and Health. Macroeconomics and health: investing in health for economic development. Geneva, Switzerland: WHO, 2001.

2 Trouiller P, Olliaro P, Torreele E, Orbinski J, Laing R, Ford N. Drug development for neglected diseases: a deficient market and a public-health policy failure. Lancet 2002;359:2188-94.

3 World Health Organization. Priority medicines for Europe and the world. Geneva, Switzerland: WHO, 2004

4 Olliaro P, Smith P. The European and developing countries clinical trials partnersip J HIV Ther $2004,9.53-6$.

partnership. J HIV Ther 2004;9:53-6.
United Nations. United Nations millennium declaration. United Nations General Assembly resolution 55/2. New York, NY: UN, 2000.
6 Duley L. Maternal mortality and hypertensive disorders of pregnancy in Africa, Asia, Latin America and the Caribbean. Br J Obstet Gynaecol Africa, Asia, Latin

7 World Health Organization. The world health report 2005. Make every mother and child count. Geneva, Switzerland: WHO, 2005.

8 Duley L, Gülmezoglu A, Henderson-Smart D. Magnesium sulphate and other anticonvulsants for women with pre-eclampsia. Cochrane Database Syst Rev 2003(2):CD000025.

9 Eclampsia Trial Collaborative Group. Which anticonvulsant for women with eclampsia? Evidence from the collaborative eclampsia trial. Lancet 1995;345:1455-63.

10 Magpie Trial Collaborative Group. Do women with pre-eclampsia, and their babies, benefit from magnesium sulphate? The magpie trial: a randomised placebo-controlled trial. Lancet 2002;359:1877-90.

11 World Health Organization. WHO model list of essential medicines. 13th edn. Geneva, Switzerland: WHO, 2003.

12 Aaserud M, Lewin S, Innvaer S, Paulsen E, Dahlgren A, Trommald M, et al. Translating research into policy in developing countries: a case study of magnesium sulphate for pre-eclampsia. BMC Health Serv Res 2005 (in press)

13 Sheth S, Chalmers I. Magnesium for preventing and treating eclampsia: time for international action. Lancet 2002;359:1872-3.

14 WHO/Unicef. Maternal mortality in 2000. Estimates developed by WHO, Unicef and UNFPA. Geneva, Switzerland: WHO, 2004.

15 Granja A, Machungo F, Gomes A, Bergstrom S, Brabin B. Malaria-related maternal mortality in urban Mozambique. Ann Trop Med Parasitol maternal morta

16 Ministry of Health and Child Welfare. Zimbabwe national health profile 2000. Harare: MoHCW (Epidemiology and Disease Control, National Health Information and Surveillance Units) in conjunction with the Central Statistical Office, 2000

17 Green J, Thorogood N. Qualitative methods for health research. London: Sage, 2004.

18 Kaplan WA, Laing R. Paying for pharmaceutical registration in developing countries. Health Policy Plan 2003;18:237-48.

19 Gravelle H, Rees R. Microeconomics. London: Prentice Hall, 2004.

20 Remarks by Governor John A Kitzhaber. States and provinces: creating a functional marketplace for prescription drugs, 11-12 Oct 2002, a functional marketplace for prescription drugs, 11-12 Oct 2002, Portland, Oregon. http://www.oregon.gov/DAS/OHPPR/ORRX/docs/
Governors_Conference_Presentations/Kitzhaber_speech_Drug_Conf_ Oct10_02_Final.pdf (accessed 16 May 2005).

\title{
Gaining a foothold: tackling poverty, gender inequality, and HIV in Africa
}

\author{
Julia C Kim, Charlotte H Watts
}

Over half of adults infected with HIV in Africa are female--but poverty and social structures still prevent many women from protecting themselves

The United Nations millennium development goals have set out specific targets for 2015, including commitments to reduce extreme poverty, increase women's empowerment, and reverse the spread of the HIV pandemic. In this respect, they clearly recognise what has been called the triple threat facing Africa: poverty, gender inequalities, and HIV and AIDS. ${ }^{1}$ Tackling these issues is clearly difficult, and many people have greeted these goals with a sense of scepticism and even futility. We describe why tackling poverty and gender inequalities is central to controlling the HIV pandemic in Africa and suggest how it might be achieved.

\section{Women and HIV}

Two years ago, the UN secretary general Kofi Annan declared that "AIDS has a woman's face." Echoing this statement, the Joint United Nations Programme on HIV and AIDS (UNAIDS) has highlighted women, girls, and HIV and AIDS as the theme for their most recent World AIDS Day campaign. Today, women account for nearly half the 40 million people living with HIV worldwide. In sub-Saharan Africa, $57 \%$ of adults with HIV are women, and young women aged
15 to 24 are more than three times as likely to be infected as young men. ${ }^{3}$

Contradictory analyses of Uganda's success in tackling HIV and AIDS have sparked debates over the relative prevention merits of promoting condoms, sexual fidelity, or abstinence. The United States has increased its funding for abstinence-only strategies, while the Catholic Church has questioned the efficacy of condoms, raising concerns about the influence of ideological or religious perspectives in shaping global priorities for prevention. ${ }^{4}$ Yet a larger question remains. Regardless of their point of emphasis, why are HIV prevention efforts continuing to fail women and girls?

The prevention messages, whether urging women to abstain, be faithful, or use condoms, often fail to reflect the reality of women's lives and, in particular, the broader social forces that contribute to their risk. In settings where limited educational or economic opportunities exist, pressures of poverty lead women and girls to trade sex for survival. Where women have low status and financial autonomy, and depend on their partners for support, abstaining from sex or negotiating use of condoms are simply not realistic options. Moreover, physical and sexual violence affect women's ability to
Rural AIDS and Development Action Research Programme, School of Public Health, University of the Witwatersrand, PO Box 2, Acornhoek 1360 , South Africa Julia C Kim senior researcher

Health Policy Unit, London School of Hygiene and Tropical Medicine, London

WC1E 7HT

Charlotte H Watts head

Correspondence to: J C Kim jkim@soft.co.za

BMJ 2005;331:769-72 